\title{
O signo linguístico entre Saussure e Benveniste: ainda de sua natureza "arbitrária" e "necessária" e sua relação com o sujeito falante/locutor
}

\author{
Jomson Teixeira da Silva Filho ${ }^{1}$ \\ Faculdade de Letras/Programa de Pós-Graduação em Letras e Linguística, UFAL, Maceió, AL, Brasil
}

Resumo: A arbitrariedade do signo se configurou como um afastamento de Benveniste em relação a Saussure, ou uma ultrapassagem daquele em relação a este, ao propor a relação necessária entre os constituintes do signo linguístico. Neste artigo, questionamos essa ultrapassagem especialmente no que tange ao sujeito na teorização saussuriana como aquilo que o próprio Curso de Linguística Geral (1916) projetou para a ciência linguística futura e um princípio que foi aplicado por Benveniste em sua teorização sobre a linguagem. Argumentamos sobre a noção de sujeito em Saussure, e ainda, sobre a interpretação de Benveniste (1976[1939]) do signo através daquilo que foi possível ao autor ter acesso dos textos saussurianos, como destaca Normand (2009). Assim, não defendemos que Benveniste ultrapassa Saussure ao propor as duas dimensões da linguagem, semiótica e semântica, mas que Benveniste soube "ler" Saussure, tomando-o como "em primeiro lugar e sempre o homem dos fundamentos" (BENVENISTE, 1976, p. 35).

Palavras-chave: Benveniste; Locutor; Relação arbitrária e necessária do signo; Saussure; Sujeito.

Title: The linguistic sign between Saussure and Benveniste: still of its "arbitrary" and "needed" nature and its relation to the speaking subject / speaker

Abstract:The arbitrariness of the Saussurian sign was configured as a departure from Benveniste in relation to Saussure, or an overcoming of it in proposing the necessary relationship between the constituents of the linguistic sign. In this article, we question this overrun especially as regards the 'subject' in Saussurean theorizing as what the Course itself designed for future linguistic science and a principle that would be applied by Benveniste in his theorizing about language. In this sense, we argue about the notion of "subject" in Saussure, and also about Benveniste's (1976 [1939]) interpretation of the sign through what made it possible for Benveniste to have access to Saussurian texts, as highlighted by Normand (2009). Thus, we do not argue that Benveniste surpasses Saussure by proposing the two dimensions of language, semiotics and semantics, but that Benveniste knew how to "read" Saussure, taking him as "first and always the man of the foundations" (BENVENISTE, 1976, p. 35).

Keywords: Benveniste; Announcer; Arbitrary and necessary relationship of the sign; Saussure; Subject.

\footnotetext{
${ }^{1}$ Doutor em Linguística pelo Programa de Pós-Graduação em Letras e Linguística da Universidade Federal de Alagoas (Ufal). Professor De Língua Portuguesa e Língua Inglesa da Rede Particular de Ensino, SEDUC e SEMED. Gostaríamos de agradecer aos pareceristas pelos significativos comentários e importantes sugestões. Orcid: http://orcid.org/0000-0001-5768-8289. E-mail: its filho@hotmail.com
} 


\title{
Considerações iniciais
}

A elaboração da arbitrariedade do signo linguístico, nos termos saussurianos, configurou-se como um ponto em que Benveniste parece se afastar de Saussure, ultrapassando-o, ao estabelecer a relação necessária e não arbitrária entre os constituintes do signo linguístico. Essa ultrapassagem é defendida pelos autores ${ }^{2}$, com base, especificamente nas seguintes passagens de Benveniste:

\begin{abstract}
Em conclusão, é necessário ultrapassar a noção saussuriana de signo como princípio único, do qual dependeria simultaneamente a estrutura e o funcionamento da língua. Essa ultrapassagem far-se-á por duas vias: na análise intralinguística e na análise translinguística dos textos e das obras... (BENVENISTE, 1989, p. 67)

Compete-nos ir além do ponto a que Saussure chegou na análise da língua como sistema significante. É necessário, de início compreender tudo o que implica em relação às noções de que nos ocupamos aqui - a noção de sentido e noção de forma - a doutrina saussuriana de signo. (BENVENISTE, 1989, p. 224).
\end{abstract}

Nunes (2011) destaca que esse "ir além" na afirmação de Benveniste "contempla o que 'sobrara' do Curso de Linguística Geral, principalmente a noção de sujeito". (p. 53, destaques da autora). Neste artigo, objetivamos questionar essa ultrapassagem especialmente no que tange ao lugar do sujeito na teorização saussuriana, não como aquilo que sobrou do Curso de Linguística Geral (doravante $\mathrm{CLG}$ ), mas como aquilo que o próprio CLG projetou para a ciência linguística futura e como um princípio que "foi aplicado" por Benveniste em sua teorização sobre a linguagem.

A partir da metáfora do "balão no ar" trazida por Saussure nos Escritos de Linguística Geral (2002) - ELG, argumentamos sobre a noção de "sujeito" em Saussure como uma limitação do arbitrário do signo (DEPECKER, 2012) e, ainda, sobre a interpretação de Benveniste (1976[1939]) do signo linguístico saussuriano através daquilo que foi possível a Benveniste ter acesso dos textos de Saussure, como destaca Normand (2009).

Nesse sentido, não adotamos a conclusão de que Benveniste ultrapassa Saussure em relação ao signo, assim como a partir da noção de locutor ao propor as duas dimensões da linguagem, semiótica e semântica. Defendemos, sim, que Benveniste, como o mais saussuriano dos linguistas (NORMAND, 2006a, p.71), soube "ler" Saussure como ninguém, mesmo sem ter tido acesso aos ELG (2002) de onde destacamos a metáfora do "balão no ar" para argumentar que Saussure também havia tratado da questão do sujeito ao teorizar sobre o signo, assim como fez Benveniste a partir da dimensão semântica da linguagem.

Saussure como continuador da Gramática Comparada: a síntese de uma epistemologia e de uma visão não estruturalista de Saussure ${ }^{3}$

\footnotetext{
2 Ao longo de nossa argumentação, trataremos com mais detalhes dos autores que defendem essa ultrapassagem.

${ }^{3}$ Esta seção reproduz e amplia a discussão feita em Silva Filho (2018).
} 
Milner (1995) afirma que a linguística deseja ser uma ciência e que é exatamente essa necessidade que vai diferenciá-la da gramática e da retórica. Ao constatar a diversidade das escolas linguísticas, o autor pressupõe que seria possível estabelecer um projeto geral de ciência da linguagem a partir da escolha de seu objeto.

É Saussure com o CLG (1916) quem opera essa escolha ou esse corte ao assumir a língua como objeto da ciência linguística. Veremos adiante com Fiorin (2013) que Saussure definiu os objetos empírico e teórico dessa ciência. Entretanto, antes de nos determos exatamente na cientificidade da linguística, gostaríamos de perpassar a concepção de ciência através das argumentações de Milner (1995 e 2012) ${ }^{4}$ para assinalar nossa decisão de assumir em Saussure uma epistemologia galileana, como um continuador da Gramática Comparada, assim como faz Faria (2018) e o próprio Milner (2012), e não como o fundador de uma nova ciência linguística. Esta assunção nos ajudará a argumentar que uma leitura estruturalista de Saussure implica uma posição teórica diferente daquela que assumimos aqui, com Neumann e Anjos (2019), de que Saussure não pode ser reduzido a interpretações estruturalistas.

Milner (2012) nos ensina que uma concepção de ciência enquanto uma produção discursiva deve ser compreendida como uma produção de proposições que combinam uma manipulação de dados empíricos de modo matematizado e o estabelecimento de uma relação entre teoria e técnica. Nesse mesmo caminho, o autor afirma que para que a linguística se constituísse como uma ciência moderna, ela precisaria atender aos critérios de matematização. Como destaca ainda o autor, a matematização do real e a manipulação técnica de uma teoria foram aspectos apresentados por Koyré (1986) que, a partir dos conceitos de Galileu-Galilei, estabeleceu sua compreensão de ciência moderna.

A matematização do real não implica quantificação de dados, mas literalização, isto é, a literalização matematizada não significa mensuração do fenômeno, e sim que o discurso científico se vale de suas próprias regras e não daquilo que elas designam, ou seja, estabelece uma escrita que permite usar símbolos tomados em si mesmo e não para sua designação. Milner (2012) denomina de "funcionamento cego" essa possibilidade de manipular os conceitos independentemente do fenômeno.

A relação entre teoria e técnica é o segundo traço destacado por Milner (2012) a partir de Koyré (1986), como vimos acima. Por meio da manipulação empírica o sujeito/cientista registra um saber que deve ser transcrito através do discurso da literalização matemática - a escrita matematizada. É neste ponto que o autor sublinha a atividade de matematização do real como o principal traço distintivo da cientificidade moderna. Faria (2018) nos traz o exemplo de Saussure sobre a reconstrução *ĕk1wŏs

\footnotetext{
${ }^{4}$ Destacamos, no entanto, que Milner assume em Saussure uma epistemologia aristotélica e não galileana. 0 que assumimos com Milner (2012) é que Saussure é um continuador da Gramática Comparada e que, essa sim, para Milner apresenta os critérios de uma epistemologia galileana. Seguimos o raciocínio segundo o qual entendemos que, se Saussure é o continuador da Gramática Comparada, ele também apresenta em suas teorizações essa epistemologia, conforme Bouquet (2010). Para mais detalhes, conferir Silva Filho (2018).
} 
(reproduzido abaixo) muito pertinente para a compreensão do que seria essa escrita matematizada:

[...] para conhecer as unidades fônicas de uma língua, não é indispensável caracterizar-lhes a qualidade positiva; cumpre considerá-las como entidades diferenciais cuja peculiaridade consiste em não se confundirem umas com as outras. Isso é de tal maneira essencial que se poderiam designar os elementos fônicos de um idioma a reconstituir por quaisquer algarismos ou signos Por conseguinte, a reconstrução de *ĕk1wŏs quer dizer que o correspondente indoeuropeu do latim equos, sânscrito açva-s etc., era formado de cinco fonemas determinados, tomados à gama fonológica do idioma primitivo. (SAUSSURE, 2008[1916], p. 259).

Tratando do "fonema", a autora, através dessa passagem, elucida que a escrita matematizada mencionada por Milner (2012) é totalmente assumida por Saussure, pois, há uma reconstrução pela escrita que toma o fonema por letra "sem que essas formas/fórmulas possam ser faladas" (FARIA, 2018, p. 886). Segundo Milner (1995), pode-se encontrar na Gramática Comparada todas as bases necessárias para determinação de uma ciência galileana, conforme também corrobora Bouquet (2000). Por isso mesmo entendemos que, se Saussure é entendido como um continuador dessa disciplina, podemos afirmar que sua epistemologia também se apresenta como tal.

Graças a sua capacidade de estabelecer cálculos, isto é, manipulação de unidades sem considerar suas substâncias, existe na Gramática Comparada a possibilidade de elaborar uma ciência da linguagem que atenda aos critérios de ciência galileana. Além disso, Milner (2012) afirma que o mérito da Gramática Comparada em relação aos estudos antecedentes é a possibilidade de uma "edificação da escrita", uma vez que "ela [a Gramática Comparada] possa notar formas por definição não observáveis, desempenhando a função matriz para um conjunto de formas observadas". (MILNER, 2012, p. 31 - grifos do autor).

Nesse sentido, entendemos com Milner (2012) que Saussure não funda uma linguística moderna, e, portanto, não pode ser lido como o "pai" do estruturalismo. Segundo o autor, e como destaca Faria (2018), "para Saussure [...] a linguística existe - é a gramática comparada -, o problema é que ela ignora aquilo que a possibilita" (p. 51). O CLG "[...] não passa da exposição das condições conceituais que tornam possível a gramática comparada" (MILNER, 2012, p. 32). Faz-se necessário então, apontar qual a relação entre o fazer científico da linguística e o próprio Saussure. Dissemos que Saussure é o continuador da Gramática Comparada. Entretanto, Saussure vai além dela, porque com ele, os estudos deixam de se concentrar apenas na comparação de manifestações externas de várias línguas.

Benveniste, em relação ao método comparativo se questiona:

Como podemos dizer de um dado linguístico, tomados em dois momentos da evolução, que é o mesmo dado? Em que reside essa identidade, e já que é proposta pelo linguista entre dois objetos, como a definiremos? É preciso um corpo de definições. (BENVENISTE, 1976, p. 36-37, destaque do autor). 
Saussure parece, então, dar um corpo ao método quando deixa de se concentrar na comparação em si e passa a entender a língua como um sistema de valores estruturado e autônomo, subjacente a toda e qualquer produção linguística. Inicialmente, Saussure conceitua a língua como um sistema de signos e, posteriormente, como um sistema de valores puros. Trataremos desse ponto adiante.

Firoin (2013) nos alerta que no CLG, ao tratar da língua, Saussure, como um primeiro gesto científico, destaca dois objetos para a ciência linguística: um objeto empírico - a linguagem - e um objeto teórico - a língua. Diz o autor:

\begin{abstract}
O primeiro gesto de Saussure, no Curso, foi definir o objeto teórico da linguística. A linguagem é a capacidade que os homens têm de comunicar-se com seus semelhantes por meio de signo. No entanto, esse é o objeto empírico da linguística, não pode ser seu objeto teórico [...] O objeto teórico é diferente do objeto empírico. Aquele é estabelecido a partir de um objeto observacional, que é a "região" do objeto empírico que será objeto de estudo [...] O objeto observacional converte-se, então, em objeto teórico. O objeto observacional recortado por Saussure é a langue. É a partir desse objeto que todos os outros conceitos desenvolvidos pelo mestre genebrino ganham sentido. (FIORIN, 2013, p. 99-100).
\end{abstract}

Adotamos, como já dissemos a posição de Milner (2012) segundo a qual Saussure é o continuador da Gramática Comparada. Devemos ter em conta, no entanto, o que destaca Bouquet (2000) sobre essa disciplina. O autor afirma que, embora produzisse resultados incontestáveis e importantes para os estudos da linguagem à época, a Gramática Comparada ignorava as condições que tornavam possíveis esses resultados, ou seja, até Saussure, não se podia afirmar a existência, nos termos do próprio Saussure, de "uma filosofia da linguística" (epistemologia nos termos atuais).

Saussure adota o ponto de vista neogramatical e assume que a linguística é uma ciência histórica e não uma ciência da natureza. Mas, essa não seria a principal contribuição de Saussure, e sim o seu grau de abstração, capaz de assumir um objeto para a ciência linguística necessário para garantir a sua legitimidade, como vimos acima a partir de Fiorin (2013). Afirma Saussure:

A primeira escola da linguística não considerou a língua em sua característica de fenômeno. É preciso dizer mais. Ela ignorou o fato de linguagem, e atirou-se diretamente à língua, ou seja, ao idioma (conjunto de manifestações da linguagem de um povo numa época), e só viu o idioma através do véu da escritura. Não há fala, há apenas conjunto de letras. Um primeiro passo se deu: da letra veio a considerar o som articulado e do papel se passou ao sujeito falante [ ]. Não há ainda linguagem, já há fala. A conquista destes últimos anos é ter, enfim, colocado não apenas tudo o que é a linguagem e língua em seu verdadeiro nicho exclusivamente no sujeito falante seja como ser humano seja como ser social. (SAUSSURE, 2002, p. 115-116). ${ }^{5}$

\footnotetext{
${ }^{5}$ Gostaríamos de esclarecer que mesmo sendo uma obra editada por Bouquet e Engler, preferimos utilizar o nome de Saussure uma vez que sabemos que é deste os escritos que foram organizados por aqueles. Obviamente, não estamos desmerecendo o trabalho dos editores, muito pelo contrário. No entanto, queremos com esta escolha, marcar a autoria saussuriana dos manuscritos.
} 
Esse objeto seria então por natureza, um objeto psicológico, uma vez que tanto a face fonológica quanto a face semântica da língua pertencem à ordem do espírito, ainda que seja de natureza concreta. É a partir dessa concepção de objeto psicológico que Saussure enuncia a dicotomia do fonético oposto ao morfológico, assim como o conceito de sincronia linguística, na medida em que um sistema de signos é um fato sincrônico e é na sincronia que o sujeito falante se encontra.

A linguística, então, passa a ser concebida como uma ciência: ela não só descreve fatos linguísticos, mas busca uma explicação coerente para sua ocorrência. Normand (2009) chega mesmo a dizer que a questão que movia Saussure era: "O que é língua?" (NORMAND, 2009 , p.34). Assim, apesar de já haver um estudo sistematizado e produtivo de comparação linguística com a Gramática Comparada, Saussure, nas palavras de Normand, decepciona-se ao perceber que:

a evidência para os linguistas é de que eles se ocupam com a linguagem e com as línguas; assim o afirmam, sem estabelecer uma relação clara entre esses dois termos, e sem que jamais se saiba se o termo linguagem representa o conjunto de línguas, uma língua qualquer que se estime valer por todas as línguas, uma faculdade (social e/ou natural) comum a todos os homens, nem qual estatuto possui uma língua concreta em relação a essa generalização. (NORMAND, 2009, p. 35-36).

Parece que é a partir da inquietação apontada por Normand (2009) - "O que é língua?" - que Saussure vai construindo uma argumentação em torno da definição de língua, assim como em torno de toda uma problematização sobre a linguística geral como um campo científico, perceptível já no capítulo III da introdução do Curso de Linguística Geral, intitulado "Objeto da linguística", em que o autor começa a discussão com uma pergunta, a saber: "Qual é o objeto, ao mesmo tempo integral e concreto da Linguística? (SAUSSURE, 2003[1916], p. 15).

O mestre genebrino, então, assume que é a língua (objeto teórico) que deve ser tomada como objeto da ciência linguística em detrimento da linguagem (objeto empírico), uma vez que somente assumindo o terreno da língua parece ser possível a formulação de uma definição "autônoma" de ciência linguística, língua essa que não se confunde com a linguagem, mas é apenas parte dela.

\section{A concepção de signo}

Na primeira parte do CLG, chamada de "Princípios Gerais", capítulo I, Saussure nos apresenta a "Natureza do Signo Linguístico". O autor inicia uma argumentação que visa a refutar a noção de língua como uma nomenclatura, afirmando que essa concepção supõe ideias preexistentes às palavras, conforme se observa na fala do autor:

Para certas pessoas, a língua, reduzida a seu princípio essencial, é uma nomenclatura, vale dizer, uma lista de termos que correspondem a outras tantras coisas. Por exemplo: 


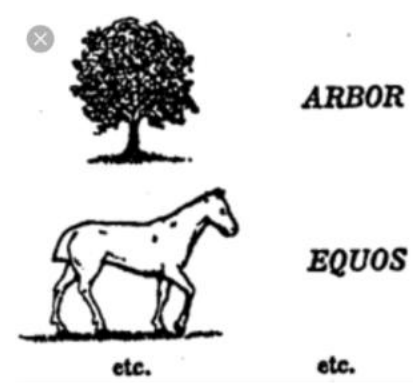

Tal definição é criticável em diferentes aspectos. (SAUSSURE, 2003[1916], p. 79)

O autor enfatiza que essa "visão simplista", embora criticável, mostra que a "unidade linguística é uma coisa dupla, constituída da união de dois termos" (p. 79). Saussure segue seu raciocínio afirmando que o signo linguístico une não uma coisa e uma palavra, mas um conceito a uma imagem acústica ( $p .80$ ), sendo uma entidade psíquica de duas faces, em que os dois elementos estão intimamente ligados.

Dessa forma, Saussure, nas palavras de Fiorin (2013), estabelece uma nova ordem dos fatos, ao afirmar que a língua é um sistema de signos que exprimem ideias, dentre outros sistemas como a escrita, o alfabeto dos surdos-mudos, os sinais militares, dentre outros, no qual o sistema da língua o principal deles, e que, portanto, seria preciso criar uma ciência geral desses sistemas, a Semiologia, da qual a linguística seria parte.

Saussure (2003[1916]) destaca a necessidade de substituir os termos "conceito" e "imagem acústica" respectivamente, por significado e significante, afirmando que esses dois termos têm a vantagem de assinalar a oposição entre si, e ainda, do total do qual fazem parte, mas não encontra outro termo para a união do significado e do significante, continuando a nomear de "signo". Para o signo, Saussure estabelece duas características ou princípios básicos: a arbitrariedade ${ }^{6}$ e a linearidade ${ }^{7}$.

Fiorin (2013) elucida que no estudo dos sistemas de signos é preciso considerar três aspectos saussurianos: a) o signo linguístico é composto por uma dupla face: o signo une não uma coisa uma palavra, mas um conceito a uma imagem acústica; b) o princípio fundamental da teorização saussuriana: o elo que une o significado ao significante é arbitrário; e c) a noção de valor, uma vez que o valor de um signo se estabelece pela diferença com outros signos no sistema numa relação de oposições e negatividade. Sendo assim, na língua só existem diferenças.

Milner (2008) afirma que Saussure não elabora uma teoria do signo propriamente dita, uma vez que Saussure toma o conceito de "signo" como um conceito primitivo que não precisa se definir. Cunha (2008) destaca que "signo" é um termo frequente nas teorizações da linguagem mesmo antes do CLG, pois pertence a uma tradição metafísica vigente nos séculos XVII e XVIII, portanto, como ressalta a autora, a definição do signo como elemento fundamental da linguagem não é nova.

\footnotetext{
${ }^{6}$ Trataremos desse conceito em detalhes na próxima seção.

7 Por questão de espaço e por não ser nosso objetivo não trataremos deste princípio. Para mais detalhes, conferir Testenoire (2010), Silva Filho (2018), além do próprio Saussure (1916 e 2002).
} 
Milner (2008), por sua vez, destaca a diferença entre as teorizações do signo em Saussure e em Port-Royal, afirmando que esta diferença se baseia especialmente na noção de assimetria em que consiste o port-royalismo: a fumaça é o signo do fogo, a respiração é o signo da vida, a expressão do rosto é o signo do sentimento, mas não inversamente. (MILNER, 2008, p. 29). Em Saussure, por sua vez, a assimetria não é absoluta, conclui Milner (2008), mas ao contrário está baseada na reciprocidade, como mostram as citações do CLG, destacadas por Milner (2008, p.29): "uma sucessão de sons só é linguística se comporta uma ideia (...) os conceitos (...) só se tornam entidades linguísticas por associação com imagens acústicas". Nos Escritos (2002), Saussure vai dizer, por exemplo, que um som sem valor linguístico é apenas uma figura vocal.

O que Saussure faz, então, é recusar uma teoria clássica de signo segundo a qual este é uma realidade que representa, numa relação assimétrica, outra realidade. É exatamente para destacar essa reciprocidade que, segundo Milner (2008), Saussure propõe a substituição dos termos conceito e imagem acústica por significado e significante, em que se destaca o fato de que não há significado sem a contra parte significante e não há significante sem um significado. De uma só vez, Saussure constrói uma argumentação sobre o signo que se afasta da noção de representação, colocando-o um conceito puramente linguístico.

Normand (2009) afirma que essa mudança na concepção de signo elaborada por Saussure é o que o afasta de ser um filósofo da linguagem, ou seja, aquele que apresenta o "signo" a partir da noção de representação de uma ideia pré-estabelecida. Longe disso, a novidade do "signo" trazida por Saussure é o que o colocaria como um "analista da língua".

Saussure ${ }^{8}$ conclui o CLG dizendo que a linguística tem por único e verdadeiro objeto a língua considerada em si mesma e por si mesma. (p.271). Como mostra Fiorin (2013), essa conclusão de Saussure lhe trouxe muitas acusações, especialmente a exclusão de suas teorizações sobre a linguagem no que tange à dimensão histórica desse fenômeno e consequentemente o sujeito.

Defendemos ainda com Fiorin (2013), no entanto, que ao definir uma ciência futura como a semiologia, ou seja, ciência que estuda os signos no seio da vida social, Saussure destacaria duas dimensões no estudo dessa ciência: "a do sistema e a do processo" (p. 105), assim como Benveniste (1976) estabelece duas instâncias de linguagem: a semiótica e a semântica. Ainda que não defendamos tomar os conceitos saussurianos e benvenistianos ${ }^{9}$ por sinônimos numa relação direta entre semiótico/sistema e semântico/processo, ressaltamos que ao tratar da dimensão do "processo", segundo nossa interpretação,

\footnotetext{
${ }^{8}$ Estamos assumindo o Curso de Linguística Geral como uma obra saussuriana independente das questões autorais que cercam sua produção.

${ }^{9} \mathrm{Um}$ parecerista, muito perspicazmente, questionou se o que estamos destacando aqui como sistema e processo em Saussure, poderiam ser relacionados às dimensões semiótica e semântica da linguagem de Benveniste. Este é um tema bastante interessante que gostaríamos de retomar em um momento mais oportuno. Por questões de espaço e objetivos, esse tema não será tratado com mais detalhes neste texto, embora apareça dentro de nossa argumentação em alguns momentos. Ressaltamos nosso agradecimento em relação à essa questão, que muito chamou nossa atenção.
} 
Saussure parece propor também que a vida dos signos dependeria de sua realização linguística num sistema inserido na comunicação social.

Se o sistema é o conceito que vai dar conta da abordagem imanente do objeto da linguística, sugerimos que em Saussure é a noção de processo que daria conta da vida dos signos em uso pelo sujeito falante, sem sair da análise formal da língua. Ao propor a dimensão semântica da linguagem, mais uma vez, Benveniste se mostra um exímio leitor de Saussure.

\section{Saussure: a natureza arbitrária do signo}

Saussure, como vimos, afirma que o vínculo que une um significado a um significante não é motivado, ou seja, não tem uma relação necessária, no sentido de que não há explicação "natural" que justifique essa união. Sobre isso, diz Saussure que,

o elo que une o significante ao significado é arbitrário, ou ainda, dado que entendemos por signo o total resultante da associação de um significante com um significado, podemos dizer mais simplesmente: o signo linguístico é arbitrário. (SAUSSURE, 1916, p. 100).

A associação é feita de forma imotivada, mesmo quando se refere a uma arbitrariedade relativa, uma vez que é relativa a outro signo que é absolutamente arbitrário. O CLG nos fornece o exemplo muito feliz da palavra "dezenove", motivada por "dez" e "nove" que, por sua vez, são absolutamente imotivadas (SAUSSURE,2003[1916], p. 152-153).

Depecker (2012) afirma que para Saussure, o princípio do arbitrário está não apenas no centro do signo, mas também no centro da língua, uma vez que todas as análises correspondentes à teorização saussuriana parecem conduzir a esse princípio. $O$ autor ainda nos diz que antes de se fixar no termo arbitrário, Saussure, nos Escritos (2002), oscilou entre os termos "convencional" e "independente". Entretanto, assumir o termo "convencional" implicaria assumir que a língua é baseada em algum tipo de convenção estabelecida de maneira consciente entre os falantes desta língua, além do fato de este termo não destacar a questão da mutabilidade do signo.

Ainda segundo Depecker (2012), o arbitrário para Saussure se apresenta sob três relações: "a relação do signo com a coisa; a relação do signo com a ideia enquanto um elemento do pensamento; a relação interna ao signo, entre forma e ideia". (DEPECKER, 2012, p. 93). No que tange à primeira relação, a arbitrariedade tem um caráter definitivo, o que faz Saussure renunciar à palavra "símbolo", já que essa expressa uma relação direta de semelhança com o objeto à qual se remete.

Sobre o segundo fato, a partir de Saussure, Depecker (2012) destaca que não existe relação entre o signo e a ideia que por ele é evocada no pensamento, pois não há explicação natural que seja capaz de justificar o elo existente entre um signo e uma ideia. A terceira relação em que se destaca o arbitrário é aquela que se dá internamente ao signo, a partir de 
seus constituintes, ou seja, não o arbitrário "do" signo, mas o arbitrário "no" signo, a relação interior do significado com o significante.

Essa afirmação da relação arbitrária entre os constituintes do signo parece implicar necessariamente a relação arbitrária entre o signo com outros signos, ou seja, entre os signos. É esse caráter da arbitrariedade entre significado e significante e entre os signos, que explicaria, segundo Saussure (1916 e 2002), o princípio da evolução das línguas. Esse fato é explicado pela assunção de que se a relação entre o significado e o significante é arbitrária uma vez que não mantém entre si uma relação de obrigatoriedade, esses constituintes "se encontram constantemente submetidos à interpretação feita pelos sujeitos falantes." (DEPECKER, 2012, p. 98, grifo nosso), ou seja, estão sempre numa mão dupla entre o sistema e o processo. Disso decorre que qualquer signo pode "desfazer" sua união, e consequentemente, que um significante pode unir-se a outro significado qualquer, reciprocamente, já que a união que resulta num signo não é "fixa, nem natural".

Sobre isso, a autora se pergunta: "a natureza do signo é dupla, mas em que consiste esta duplicidade? Um significante está irremediavelmente "colado" a um significado que the é correspondente?" (p. 3). A ideia de que um significante está colado a um significado, remeteria a noção de língua como uma nomenclatura. Como se sabe a partir do CLG e de acordo com o que vimos acima, Saussure renuncia radicalmente a noção de língua como etiqueta. Concordamos com a autora ao dizer que é a noção de arbitrariedade que responde as questões acima.

A arbitrariedade também se apresenta como uma explicação para o caráter mutável da língua, já que significantes podem unir-se a novos significados desfazendo a união e renovando-a continuamente. É nesse sentido que se pode dizer com Saussure que o princípio da evolução da língua é explicado a partir da própria estrutura do signo. Um paradoxo se impõe: como é possível ao sistema da língua manter-se tendo como característica fundamental a arbitrariedade de seus signos? Como resposta a essa indagação, Depecker (2012) apresenta aquilo que ele chama de "limitações do arbitrário". Sobre isso, trataremos na última seção. Adiantamos a síntese do autor sobre a relação entre os constituintes do signo e entre os signos: "relação arbitrária, portanto, e no entanto, necessária". (DEPECKER, 2012, p. 104).

\section{Benveniste: a natureza necessária do signo}

Esta seção é iniciada com uma expressão que já se destaca no título deste texto, a saber, a natureza necessária do signo linguístico. O que estamos chamando de "necessária" aqui, diz respeito exatamente a um contra-argumento à noção de "signo arbitrário", conforme explicitamos na seção acima. Vejamos o que diz Benveniste (1976) no início de seu texto "Natureza do Signo Linguístico":

É de F. de Saussure que procede a teoria do signo linguístico atualmente afirmada ou implicada na maioria dos trabalhos de linguística geral. E é como uma verdade 
evidente, não ainda explícita, mas incontestada na realidade, que Saussure ensinou que a natureza do signo é arbitrária. A fórmula impôs-se imediatamente. Toda afirmação sobre a essência da linguagem ou sobre as modalidades do discurso começa por enunciar o caráter arbitrário do signo linguístico. O princípio tem tal alcance que uma reflexão que verse sobre qualquer parte da linguística o encontra necessariamente. Os fatos de que seja invocado em toda parte e dado sempre por evidente são duas razões para que se procure ao menos compreender em que sentido Saussure o tomou e a natureza das provas que o manifestam. (p. 53)

Benveniste trata do princípio da arbitrariedade do signo linguístico apresentado por Saussure, atribuindo a esse princípio tamanha importância que chega a dizer que toda afirmação sobre a essência da linguagem encerra como por anunciar o princípio do arbitrário e, que por isso, deve-se tentar compreender sua natureza. O autor nos diz que não tem a intenção de contradizer a bifurcação no conceito de signo e, ainda, que concorda com a definição de língua como uma forma e não uma substância, conforme Saussure apresenta no CLG.

Entretanto, o autor começa a argumentar sobre a arbitrariedade para contrapô-la. Defende, então, que a relação entre as partes constitutivas do signo linguístico apresenta um caráter necessário, "[E]ntre o significante e o significado, o laço não é arbitrário; pelo contrário, é necessário". (BENVENISTE, 1976, p. 55, grifos nossos). Dessa forma, o autor conclui que o que há de arbitrário é a relação entre o signo e a sociedade, mas não a relação entre o significado e significante.

Ao tratar dos exemplos de Saussure (CLG, 2003[1916], p.82) sobre a diferença entre $b$-o-f e o-k-s, Benveniste afirma que o mestre genebrino traz ao debate o elemento que foi excluído da teorização do signo, a saber, a coisa ou a realidade. Ao defender esta tese, Benveniste coloca o signo linguístico sob o ponto de vista do locutor, ou seja, sob o ponto de vista do discurso ou da língua em uso, já que nesse caso, para o falante da língua, parece haver uma positividade necessária atrelada ao signo para que a língua, ou mais especificamente, o locutor/sujeito falante possa reconhecê-lo. Diz Benveniste: "[P]ara o falante há, entre a língua e a realidade, adequação completa: o signo encobre e comanda a realidade; ele é essa realidade.. (p. 57).

Como argumentam Agustini e Leite (2012), Benveniste (1976) através do próprio Saussure e baseando-se nos exemplos do CLG quando da explicação da natureza arbitrária do signo linguístico, coloca em outros termos e a partir de outras dimensões da linguagem, o princípio da arbitrariedade. Os autores defendem que o princípio do arbitrário do signo não foi abandonado por Benveniste, que o problematiza "tendo em vista a natureza dos aspectos que ele contemplou em sua teoria: o uso da língua, a relação (inter)subjetiva da linguagem, o fato linguístico da significação, dentre outros aspectos" (AUGUSTINI; LEITE 2012, p. 119).

Ao destacar esses aspectos, Benveniste considera de forma radical o valor social que o signo só adquire quando do seu emprego enquanto signo na língua em uso, de forma que não pode haver signo senão em um ato de fala, o que faz com que Benveniste "chegue ao 
discurso, à linguagem", estabelecendo "um novo domínio: o do discurso", como destacam Barbisan e Flores (2012). Flores e Endruweit (2012) chegam mesmo a afirmar que é o "homem na língua" que se apresenta como o axioma de base da reflexão benvenistiana.

Somente do ponto de vista do linguista enquanto um "analista da língua" é que se é possível apreender o signo como entidade em potencial, contingente e arbitrária, uma vez que na consciência do sujeito falante o signo já está consubstanciado de valor social. A argumentação de Benveniste caminha para destacar que do ponto de vista do locutor não há possibilidade de exemplificação do signo linguístico, o que faz o autor entender que a exemplificação do signo no CLG apresenta um caráter de "contradição constitutiva", já que

fatalmente, o investimento na exemplificação do signo linguístico e de sua natureza arbitrária, a partir de signos em uso, em vez de ilustrar o valor sistêmico - dimensionando ali as características do valor linguístico que recaem sobre as variáveis: relação, oposição e negação -, se é que os exemplos per se contemplariam esse dimensionamento, privilegiou, de certa maneira, o valor social (isto é, a herança compartilhada que subjaz à estabilização do uso de um signo linguístico, por exemplo). (AGUSTINI; LEITE, 2012 p. 120).

Benveniste destaca que, ao elencar exemplos para evidenciar o caráter arbitrário da relação entre o significado e o significante, Saussure o faz a partir de signos já positivados, colocados no funcionamento da língua e atrelados ao valor social vinculado à realidade, fato que "nega" a natureza radical da arbitrariedade, já que como vimos, só se tem acesso ao signo quando do seu emprego num ato de fala, ou seja, a partir do ponto de vista do sujeito. Sobre isso diz Benveniste: "Na verdade, o prisma do sujeito e o do linguista é tão diferente a esse respeito que a afirmação do linguista quanto ao arbitrário das designações não refuta o sentimento contrário do falante". (1976, p. 57).

Ainda sobre isso, diz-nos Agustini e Leite (2012):

Para o locutor, portanto, a relação entre significado e significante, na constituição do signo linguístico, é uma relação necessária; no entanto, trata-se de uma solução instintiva e, por isso, não científica, não teorizada. Do ponto de vista do linguista, por sua vez, a arbitrariedade fundante do signo linguístico é não-demonstrável, porque o signo sempre-já é signo e, por isso, traz em sua constituição a relação necessária, para que haja signo, entre significante e significado. (p. 121, grifo nosso).

Das palavras dos autores, podemos entender que, o que é possível de exemplificação não é exatamente a relação arbitrária do signo, mas a possibilidade de que o signo possa relacionar uma referência social a um elemento da realidade e não a outro, sendo esse o verdadeiro caráter contingencial de um sistema linguístico específico. Como diz Benveniste

Mas o signo, elemento primordial do sistema linguístico, encerra um significante e um significado cuja ligação deve ser reconhecida como necessária, sendo esses dois componentes consubstanciais um com o outro. O caráter absoluto do signo 
linguístico assim entendido comanda, por sua vez, a necessidade dialética dos valores em constante oposição, e forma o princípio estrutural da língua. (1976, p. 59 , grifos do autor).

A natureza necessária da relação constitutiva do signo linguístico entre o significado e significante, para Benveniste, dá-se exatamente para que o signo possa cumprir sua função social de colocar em relação através da linguagem um homem com outro homem, a (inter)subjetividade, sob a perspectiva da língua em uso, transformando a relação entre o significado e o significante de contingente à necessária, "saussurianamente, poderíamos afirmar que o laço fronteiriço entre contingência e necessidade é semelhante a uma folha de papel: "[...] não se pode cortar um sem cortar, ao mesmo tempo, o outro [...]" (AGUSTINI; LEITE, 2012, p. 124).

Dissemos acima que Benveniste encontra nos exemplos de Saussure para explicitação da relação arbitrária entre o significado e significante uma contradição constitutiva. Isso se dá porque na medida em que Saussure conceitua o signo como a união de um significado e de um significante, essa entidade, o signo, é encarada como uma realidade estritamente linguística que não estabelece relação com o mundo exterior, com a realidade.

Normand (2012) trata de Saussure e Benveniste a partir de "encontros" entre esses autores. A autora ressalta que sempre que esses dois autores são postos em xeque, isso é feito pela via de discursos. Esses discursos podem ser assim listados: a) o discurso da filiação, b) o discurso da novidade, c) o discurso da comparação, d) o discurso da interdisciplinaridade e, e) o discurso da instituição universitária. Normand (2012) prefere falar de "encontros". Diz a autora:

\footnotetext{
Será abordada aqui uma relação diferente: falaremos de encontros. Benveniste encontrou Saussure no que pôde conhecer de seus escritos; muitos linguistas, talvez todos, pelo menos na França, encontraram ambos em escritos que se tornaram mais que abundantes: textos, manuscritos, glosas e comentários. Mais do que referências, tratar-se-á de presenças: ambos se impuseram e se impõem ainda hoje pra quem se interessa por linguagem. Cada um deles, mais do que revelar, levou os outros a pressentirem que algo essencial estava em jogo ali, naquilo que continua sem ser consensualmente nomeado: língua, discurso, comunicação... (p. 198, grifos nossos).
}

Ao afirmar que Benveniste encontrou Saussure, a autora coloca algo que de perto nos interessa de modo peculiar. Queremos destacar que Benveniste encontrou Saussure, mas o encontrou "naquilo que ele pode conhecer de seus escritos". Voltaremos a isto na seção que se segue. Adiantamos que mais do que encontrar Saussure para ultrapassá-lo, Benveniste soube como ninguém "ler" Saussure no CLG de uma forma muito singular, mesmo sem ter acesso aos Escritos (2002).

A questão para Benveniste parece ser o fato de que era preciso separar o ponto de vista do locutor/sujeito e o ponto de vista do linguista, já que para aquele a relação formasentido está alicerçada numa realidade discursiva, uma vez que é o signo dentro de um 
sistema linguístico que "chega" até a consciência do sujeito falante, por isso a síntese benvenistiana: "é um homem falando com outro que encontramos no mundo." (BENVENISTE, 1976, p. 285).

\section{Colocando o balão no ar: o encontro Saussure-Benveniste a partir do sujeito-locutor e sua relação com o signo linguístico nas dimensões semiótica e semântica}

Todo esse percurso intra-teórico à teorização saussuriana no que toca à sua epistemologia e cientificidade da linguística (segunda seção), ao conceito de signo (quarta seção), a natureza arbitrária (Saussure) e necessária (Benveniste) do signo (quinta e sexta seções), objetivou a chegada desta última seção em que procuraremos amarrar esse percurso a partir do encontro de Benveniste-Saussure, especialmente no que tange ao conceito de "locutor" benvenistiano a partir do ponto de vista semântico, discursivo, e de "sujeito" em Saussure através da noção de valor, sob a perspectiva metafórica do "balão no ar" dos Escritos (2002) citada por Depecker (2012) e abordada Cunha (2008).

A noção de sujeito em Saussure é uma noção cara frente à sua teorização, especialmente para aqueles que adotam uma leitura "estruturalista" do autor, muito particularmente pelo fato de este ser acusado de ter excluído a história, o referente e consequentemente, o sujeito de sua linguística, como enfatizamos acima. O próprio Milner (1987) defende que a teorização de Saussure tende a uma falta que se percebe na prisão à forquilha da completude e da não-completude, falta essa, que nas palavras do autor é adjetivada como "irremediável". Como destaca Lima (2013), aqueles que têm alguma intimidade com as leituras de Milner ${ }^{10}$, sabem que essa falta diz respeito à presença de um sujeito.

Falamos acima daqueles que adotam uma leitura estruturalista de Saussure. Para estes, Saussure, ao teorizar sobre a língua como um sistema imanente que conhece apenas sua ordem própria, teria excluído dela tudo que diz respeito ao sentido por este comportar algo da ordem do subjetivo e do não-classificável. No entanto, Neumann e Anjos (2019) nos lembram da feliz citação de Normand (2009) sobre Saussure, que aponta na discussão deste autor, para a concepção de gramática, em que se percebe um direcionamento a respeito do sentido. Para Saussure "quem diz gramática diz sincrônico e significativo". (NEUMANN; ANJOS, 2019, p. 325).

A questão do sentido é tratada por Benveniste no texto "Semiologia da língua"11. Neste texto, o autor afirma que é necessário ultrapassar Saussure no que tange ao conceito

\footnotetext{
${ }^{10}$ Não nos deteremos na análise milneriana dessa questão, aqui citada através dele por ser esse um importante leitor e exegeta da obra de Saussure e, dessa forma, nenhuma de suas considerações deve ser considerada ingênua ou mal interpretada. No entanto, as análises de Milner extrapolam os objetivos desse texto, por isso remetemos o leitor a Milner (1987) que, especialmente nessa obra, destaca a concepção de um não todo como possibilidade de relacionar o discurso da Linguística com a da Psicanálise Lacaniana.

${ }^{11}$ Aqui, utilizaremos a data de 1976 que corresponde à obra que estamos consultando. Vale ressaltar que esse texto é originalmente publicado em 1939.
} 
de signo como um princípio único, como vimos acima. Para que essa ultrapassagem possa acontecer, é necessário traçar dois caminhos diferentes ou duas dimensões: a dimensão do semiótico, que diz respeito ao sistema de valores arbitrários, e a dimensão do semântico ou da significância, que diz respeito ao discurso. Benveniste trata dessas duas dimensões ao abordar as concepções de Pierce e Saussure em relação ao signo, ao sistema da língua e da prospecção à futura ciência que teria o signo como objeto de estudo, a Semiologia. O autor destaca que se Peirce não se ocupa em teorizar sobre a língua especificamente, Saussure, por sua vez, parte da língua como objeto e aborda o signo do ponto de vista interno ao sistema linguístico.

Conforme destacamos anteriormente com Fiorin (2013), a língua é o sistema semiótico principal dentre os outros sistemas. Segundo Benveniste, isso se dá exatamente pelo seu caráter singular de significação, já que a língua é o único sistema semiótico capaz de interpretar os outros sistemas e o seu próprio, assim como também a realidade através de sua característica de dupla significância por meio de seus dois modos de significação, o semiótico e o semântico.

Como destacam Barbisan e Flores (2012), Benveniste mostra que a linguagem é a atividade significante por excelência. Nesse sentido, a significação não é algo que se acrescenta à língua, mas "é o seu próprio ser". (p. 15). Os autores nos ensinam, no entanto, que a língua apresenta um caráter diferente, pois estabelece uma realização por meios fônicos que, por sua vez, depende do sentido. Os autores afirmam que ao concordar com Saussure, Benveniste buscar ir além dele no que tange à concepção de língua como um sistema de signos, corroborando com a ideia de ultrapassagem entre os autores.

\begin{abstract}
O signo como unidade semiótica deve ser entendido do ponto de vista da forma e do sentido, já que é constituído de um significante e um significado. O significante, explica Benveniste, é o aspecto formal do signo, é a forma sonora que condiciona e determina o significado (PGL II, p. 220). A significação do signo é definida pela comunidade de fala. É no uso da língua que um signo tem existência (PGL II, p.222). Então tudo que se relaciona ao semiótico pode ser identificado no seio e no uso da língua. Semiótico é intralinguístico. Ser distintivo, num signo, é ser significativo. (BARBISAN e FLORES, 2012, p. 15, grifos dos autores).
\end{abstract}

Autores como Normand (1996) e Stumpf (2010) afirmam que Benveniste pode ser encarado como um continuador de Saussure, mas que aquele ultrapassa este, como também destacam Barbisan e Flores (2012) a partir do próprio Benveniste. Essa ultrapassagem se daria exatamente pela consideração do sujeito em Benveniste, que mesmo mantendo a definição de língua como um sistema de signos, como o fez Saussure (1916), "se dá conta da insuficiência dessa concepção para explicar os fatos que o intrigam." (STUMPF, 2010, p. 9).

Segundo a autora (STUMPF, 2010), ao estabelecer uma reformulação da significância da língua em duas dimensões, a semiótica e a semântica, Benveniste além de entender a língua como um sistema de signos, parece dar conta, com a dimensão semântica, da língua 
em uso, e, consequentemente, do sujeito excluído por Saussure em sua teorização. Nesse sentido, Normand (2009) afirma que

[É] impossível (sempre do ponto de vista do locutor) separar som e ideia, significado e significante [...] o ponto de vista dessa reflexão linguística é que todo locutor, em um dado momento, fala do mundo ou compreende o que se diz pela intermediação de sua língua. (p. 63).

Ao adotar a língua como objeto da linguística em detrimento da fala, Saussure foi acusado de excluir o sujeito, já que como lemos no CLG, a língua é parte social da linguagem enquanto que a fala é a parte individual e acidental e por isso mesmo não poderia apresentar-se como um objeto passível de classificação. Entretanto,

a observação de Saussure aponta para a interdependência de língua e fala, não para uma cisão. Se há no CLG uma separação entre os dois objetos, este se dá claramente do ponto de vista metodológico, para fins de pesquisa. Por conseguinte, podemos pensar em um sujeito implicitamente presente na concepção saussuriana de língua. (NEUMANN; ANJOS, 2019, p. 325, grifo nosso).

Os autores defendem que a ultrapassagem de Benveniste em relação a Saussure se dá exatamente pela inclusão de Benveniste daquilo que Saussure excluiu de sua linguística. Barbisan e Flores (2012) afirmam que se metodologicamente, como também destacam Neumann e Anjos (2019), Saussure priorizou o estudo da língua como objeto da linguística, Benveniste mesmo partindo de Saussure, chega à linguagem, ao estabelecer uma prioridade para o sentido e o discurso, em contraste à metodologia saussuriana que prioriza a forma. Barbisan e Flores (2012) chegam mesmo a dizer que "concordando com Saussure, ele (Benveniste) continuará a definir a língua como um sistema de signos, mas pretendendo ir além de Saussure". (p. 15).

Assim, ao estabelecer os dois domínios da língua, Benveniste argumenta que o semiótico diz respeito ao signo como fazendo parte do sistema da língua, ou seja, "é a significância da língua-sistema". (ROSÁRIO, 2018, p. 446). O semântico, por sua vez, referese à língua em seu funcionamento discursivo, ou seja, "a significância da língua-discurso". (ROSÁRIO, 2018, p. 446). Sendo a língua um sistema que possui dois domínios diferentes, é necessário que se tenha para cada um deles um aparelho conceitual específico. $O$ aparelho conceitual do semiótico está alicerçado em Saussure, a partir de sua teoria do signo. 0 semântico, por sua vez, necessita de um novo aparelho que leve o linguista a teorizar levando em conta o discurso e a enunciação.

Mais uma vez destacam Barbisan e Flores (2012) que o signo entendido a partir do ponto de vista do semiótico deve ser pensando através da forma e do sentido, uma vez que nesse caso o signo é constituído de um significado e um significante. A significação do signo é definida pela comunidade de fala, já que como destaca o próprio Benveniste (1976) o signo como unidade semiótica só tem existência no uso da linguagem, de onde conclui os autores 
que tudo que é relacionado ao semântico na língua deve ser identificado "no seio e no uso da língua". (BARBISAN; FLORES, 2012, p. 15). Destacam ainda, os autores:

Na língua há o sentido e a forma, o semântico e o semiótico, as funções de comunicar e de significar. O semântico é a língua em uso, descrição e raciocínio, não mais o significado do signo, mas do intentado. Há mudança radical de perspectiva do semiótico para o semântico: com o signo se tem o significado, em relação paradigmática de substituição, a realidade intrínseca da língua; com a frase se está no domínio do sintagma, da conexão, das coisas fora da língua, na referência à situação do discurso. Assim o sentido da frase é a ideia e as palavras que a compõem têm emprego. (BARBISAN; FLORES, 2012, p. 15).

Dessa forma, é pela enunciação que a língua se transforma em discurso, sendo a enunciação o processo pelo qual o locutor se apropria do aparelho formal da enunciação e, pela língua, se enuncia. É pela noção de enunciação que Benveniste consegue articular forma e sentido. $\mathrm{O}$ aparelho formal da enunciação seria então um dispositivo que têm as línguas e que pela sua própria estrutura é disponibilizado para que o locutor se enuncie como sujeito. Assim, através de uma análise formal, ou seja, sem criar uma linguística da fala em oposição a uma linguística da língua, Benveniste parece resolver a questão da relação entre o sistema imanente da língua e o discurso e, consequentemente, o sujeito.

Esse aparelho seria então da ordem da linguagem, já que para Benveniste não há de fato uma relação dicotômica entre as noções de língua e fala, ou seja, elas não se opõem. 0 aparelho formal da enunciação comporta tanto a língua quanto a fala. Os autores concluem seu texto com algumas afirmações muito pertinentes:

O que nos interessa dessa reflexão é situar uma interdependência entre língua e fala que, em Benveniste, recebe a forma de um princípio: o de que se deve partir dos fatos da fala para atingir o sistema da langue e que nesta esta contido o uso que aquela promove [...] Nesse caso, a existência ou não do signo e de seu sentido está diretamente na dependência de que ele possa ser usado por aqueles que falam a língua, aqueles para quem uma língua é a língua, ou seja, para o sujeito [...] Em Benveniste, o significado do signo linguístico comporta o uso da língua, logo o valor, inerente ao sistema, decorre da influência que o uso tem sobre esse sistema. (BARBISAN; FLORES, 2012, p. 19).

Parece-nos, no entanto, que essa assunção já estava em Saussure (2003[1916]) quando diz:

Sem dúvida, esses dois objetos (língua e fala) estão estreitamente ligados e se implicam mutuamente; a língua é necessária para que a fala seja inteligível e produza todos os seus efeitos; mas esta é necessária para que a língua se estabeleça. (p. 27).

Mas é a Benveniste que Barbisan e Flores (2010) recorrem para destacar que "é no uso da língua que um signo tem existência; o que não é usado não é signo; e fora do uso signo não existe. Não há estágio intermediário; ou está na língua, ou está fora da língua". (BARBISAN; FLORES, 2010, p. 19). 
Gostaríamos agora de passar a discutir a metáfora "do balão no ar" destacada nos títulos do texto e da presente seção. Não por acaso, fazemos isto neste ponto, pois defenderemos que esta metáfora saussuriana nos Escritos se relaciona de forma muito particular com as afirmações de Barbisan e Flores (2012) a respeito da ultrapassagem (ou não-ultrapassagem, no nosso caso) de Benveniste em relação a Saussure no que toca à passagem da língua do ponto de vista semiótico para o semântico e por consequência, da língua ao discurso pelo locutor/sujeito falante.

Acima dissemos que Benveniste soube "ler" Saussure a partir daquilo que foi possível a ele ter acesso de seus escritos. Justificamos essa afirmação trazendo agora o que Depecker (2012) e Cunha (2008) argumentam a partir dos Escritos (2002). Buscamos argumentar, como as análises de Benveniste e as de Saussure nos Escritos se aproximam de tal forma que podemos dizer, segundo nossa interpretação, que mesmo sem ter acesso aos manuscritos saussurianos, Benveniste foi capaz de encontrar no CLG a teorização presente naqueles textos.

Cunha (2008) no artigo "A relação significado e significante em Saussure", já citado, traz uma discussão muito pertinente em relação à arbitrariedade do signo e sobre a noção mesma de signo linguístico. A autora divide as seções de seu texto com títulos que remetam à metáfora do "balão no ar" presente nos Escritos. De início, Cunha (2008) já afirma que "devemos partir da noção de signo que nos conduzirá consequentemente à questão dos valores do sistema linguístico e do sujeito". (p. 1, grifo nosso).

Ao tratar da natureza do signo nos ELG, Saussure apresenta a metáfora que destacamos junto a Cunha (2008). A autora nos traz a seguinte citação:

\begin{abstract}
O signo, soma, sema, etc. só se pode, verdadeiramente, dominar o signo, segui-lo como um balão no ar, com a certeza de reavê-lo, depois de entender completamente a sua natureza, natureza dupla que não consiste nem no envoltório e também não no espírito, no ar hidrogênio que insufla e que nada valeria sem o envoltório. $O$ balão é o sema e o envoltório o soma, mas isto está longe da concepção que diz que o envoltório é o signo, e o hidrogênio a significação, sendo que o balão, por sua vez, nada é. Ele é tudo para o aerosteiro, assim como o sema é tudo para o linguista. (SAUSSURE, 2002, p. 102-103).
\end{abstract}

Segundo a autora, essa metáfora destaca o fato de que, mesmo para Saussure, o conceito de signo era um conceito muito difícil de apreender, por isso ele mesmo afirma que o signo é um balão no ar que, por sua vez, nada é. O linguista só pode dominar o signo como um aerosteiro que segue o balão no ar, mas que só consegue reavê-lo quando esse balão estiver em terra, ou seja, quando deixar de ser o que é.

Cunha (2008) afirma que o que diferencia o balão no ar e o balão em terra é que em terra o aerosteiro pode dissecá-lo, como se faz a um corpo sem vida. Diz a autora que "para entender a natureza dessa relação entre significantes e significados, devemos dissecar o signo, como um balão sem vida." (p. 5). No entanto, a autora chama a Saussure (2002) para nos prevenir de que, diferente do que acontece a um cadáver, mesmo que este seja um corpo sem vida, ele mantém sua anatomia. Em relação aos signos, anatomia e fisiologia se 
confundem, exatamente por conta do principio da arbitrariedade, que coloca a natureza do signo em sua fisiologia, no seu funcionamento. A anatomia do signo - o que o signo é - se confunde com a sua fisiologia - o seu funcionamento.

A autora nos diz que a metáfora do signo comparado a um balão no ar, reflete a preocupação de Saussure em identificar a natureza dupla do signo, rejeitando, como vimos acima, a noção de língua como uma nomenclatura. Como resposta a essa problemática, Saussure estabelece a arbitrariedade, que defende radicalmente a não naturalidade da união e da relação, que é sempre imotivada. Por isso, lembra a autora, a partir de Saussure: "Mas há, entretanto, o perigo de que um cadáver continua coisa organizada em sua anatomia, enquanto que, na palavra, anatomia e fisiologia se confundem por causa do princípio da convencionalidade." (SAUSSURE, 2002, p. 96).

Para melhor compreender a natureza da relação e posteriormente argumentar sobre o que "coloca o balão no ar", a autora faz referência aos Escritos sobre a dupla essência da linguagem, que aqui estamos chamando de "figura visão habitual e visão proposta", na qual a autora nos apresenta o seguinte gráfico retirado de Saussure (2002, p. 42):

Supõe-se que existem termos duplos que comportam uma forma, um corpo, um ser fonético - e uma significação, uma idéia, um ser, uma coisa espiritual. Dizemos, antes de tudo, que a forma é a mesma coisa que a significação. E que esse ser é quádruplo.

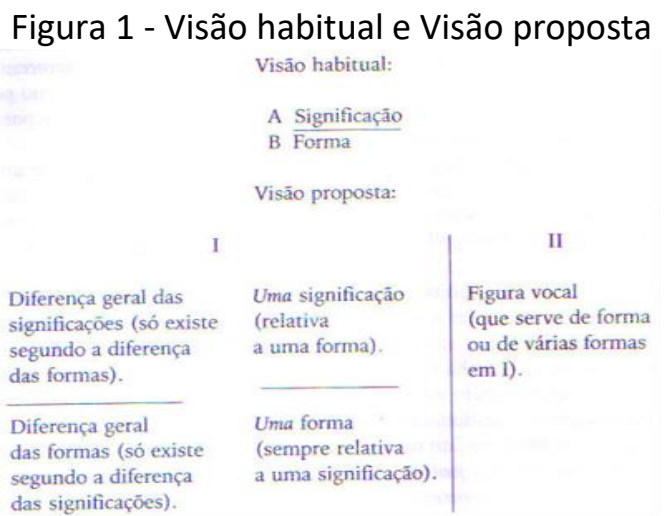

Fonte: Saussure (2002, p. 42).

Interessante notar que essa passagem destacada pela autora, corrobora exatamente com a assunção de Milner (2003) de que a novidade de Saussure em relação ao signo é de negar qualquer noção de signo como representação de uma realidade, rompendo assim com o conceito estoico e propondo a noção de diferença. Cunha (2008) nos alerta que a natureza dupla da linguagem não se refere apenas a dois termos, significação e forma, rompendo com a visão habitual. "Saussure, conhecido pelo desenho do signo, o coloca, mas apenas para negá-lo, para dizer que há algo distinto, som e sentido, mas não é apenas isso a natureza do signo." (CUNHA, 2008, p. 6).

A autora continua argumentando que a natureza dupla da unidade linguística está baseada em quatro diferenças e não em quatro termos definidos. Rompendo com a "visão 
habitual", as unidades de Saussure não são a significação e a forma, não são positivas, mas só existem em virtude das diferenças que opõem umas as outras. Diz Cunha (2008, p. 6-7):

\begin{abstract}
O professor continua a usar a oposição significação e forma, mas nos diz que a unidade está na "diferença geral das significações", sob "a diferença geral das formas", sendo que cada unidade formada de "diferenças gerais" só existe "segundo a diferença" do seu oposto. Assim, a diferença geral das significações está para "uma significação (relativa a uma forma)", e a diferença geral das formas está para "uma forma (sempre relativa a uma significação)". Podemos perceber a unidade linguística de Saussure como relativa e diferencial. (Destaques da autora).
\end{abstract}

Cunha (2008), semelhantemente a Milner (2008), conclui que a novidade de Saussure não estava exatamente na teorização sobre o signo, visto que essa noção já existia antes do professor genebrino. A novidade de Saussure se apresenta exatamente na noção de valor, nas relações de diferenças relativas e negativas, de onde se pode concluir, afirma Cunha (2008) que o que se segue no ar, assim como o balão, não são os signos, mas os valores, uma vez que Saussure não teorizava sobre os signos, mas sobre os valores.

O que coloca os signos no ar são os sujeitos falantes, na medida em que não existe uma anterioridade do signo. Este só existe no momento em que é empregado no sistema pela massa falante; fora do uso não existe signo, mas apenas no momento de seu emprego, do corte, na sincronia, como bem entendeu Benveniste (1976) ao afirma que fora do uso não há signo. É a partir do corte que o signo se constitui a partir de relações diferenciais. Os signos não existem sozinhos, mas apenas por meio da diferença. Daí a passagem da definição de língua como um sistema de signos, para um sistema de valores puros (SAUSSURE, 1916). Cunha (2008) conclui que as unidades empíricas da língua são os valores, que só abstratamente, podem ser lidos como signos.

Nesse sentido, ainda se torna interessante retornar as análises de Depecker (2012) sobre essa temática a partir dos ELG. Retomando a questão da arbitrariedade, o autor ressalta que se a relação entre significado e significante é arbitrária, seria difícil tomar essa relação como sendo de total de independência entre esses constituintes, uma vez que como destaca Saussure (2002) à página 64, eles estão indissoluvelmente unidos em nosso espírito.

O arbitrário, dessa forma, encontra uma limitação na consciência e no espírito. Esta última noção, a de "espírito" pode ser substituída pela noção mesma de "sujeito falante", como destaca Depecker (2012). É o sujeito falante que atribui valor, sentido, a um elemento linguístico, a um signo. É o sujeito falante que coloca o "balão no ar", já que é a consciência do sujeito falante o fator responsável por atribuir uma ordem a um sistema que, por ser radicalmente arbitrário, "de outra forma seria apenas um grande caos". (DEPECKER, 2012. p. 100).

Ainda nos manuscritos saussurianos, Depecker (2012) encontra outra possibilidade de "compensar" o princípio da arbitrariedade, a saber, a dimensão social da língua. O autor traz a citação muito feliz dos Escritos à página 102, quando Saussure afirma que a língua é "o resultado incessante da ação social", já que é a compreensão estabelecida entre os sujeitos 
falantes que permite à língua ser, de fato, uma língua, à semelhança da definição de língua como instrumento da comunicação de Benveniste.

É exatamente a função de comunicação entre os falantes da língua, que apresenta a necessidade de compreensão, já que som e ideia estão indissoluvelmente ligados em nosso espírito, de forma que à sequência de sons de um signo está associada na consciência do falante uma ideia que retorna a essa sequência de sons, uma vez que para existirem, os signos precisam ser apreendidos pelo espírito, por isso, "relação arbitrária, portanto, e no entanto necessária: paradoxo". (DEPECKER, 2012, p. 104).

Parece ser nesse sentido que Normand (2004) nos faz relembrar a máxima de Saussure: "quem diz signo, diz significação, quem diz significação, diz signo". Isso quer dizer que no momento em que o signo perde suas significações, ou seja, quando é tomado isoladamente, esse signo se torna apenas figura vocal, um som desprovido de sentido. É a consciência, o sujeito falante, locutor, que atribui sentido ao signo, de forma que podemos assumir, ainda em Saussure, que a língua se estabelece na e pela consciência do sujeito falante.

Assim nos diz Depecker (2012):

se nos questionarmos sobre a maneira pela qual um fenômeno como a língua, ainda que fundado no arbitrário, pode existir: o recurso extremo, na medida em que não há relação entre signo e objeto a designar, entre palavra e significação, entre som e sentido, reside nos "sujeitos falantes". E sua consciência é depositária do real, do concreto, do que é vivo na língua. (p. 117, destaques do autor).

Sobre o que é o real a que Depecker faz referência na citação acima, é o próprio Saussure quem pode nos dá essa resposta. Diz o autor que "o que é real, é aquilo de que os sujeitos falantes têm consciência em um determinado grau." (SAUSSURE, 2002, p. 183).

\section{Considerações finais}

No início de nossa argumentação, dissemos assumir a posição de Milner (2012) e Faria (2018) de que Saussure não funda uma nova ciência, mas continua a ciência sistematizada pela Gramática Comparada e que por isso, entendemos a epistemologia saussuriana como uma epistemologia galilena. Essa assunção se justifica na medida em que quisemos apresentar uma leitura não estruturalista de Saussure para tratar da noção de sujeito na teorização do autor como uma limitação do arbitrário do signo, conforme nos avisa Depecker (2012).

A partir de nossa chave de leitura, não entendemos que Benveniste ultrapassa Saussure ao estabelecer as duas instâncias de linguagem, a semiótica e a semântica, e a partir disso chegar ao discurso através do locutor e da (inter)subjetividade. Através de Normand (2004), defendemos que Benveniste encontrou Saussure "naquilo que ele pode conhecer de seus escritos". Nesse sentido, Depecker (2012) destaca que a interpretação de 
Benveniste em $1976^{12}$ é compreensível na medida em que este autor não teve acesso aos escritos de Saussure sobre essa questão, mas que mesmo assim, ainda que por vias de crítica e "ultrapassagem" soube colocar em xeque de forma muito peculiar a relação entre o significado e o significante, ao afirmar que essa relação não é arbitrária, mas necessária, ao separar os pontos de vista de locutor e do linguista.

Benveniste (1976) coloca a questão do signo levando em consideração dois pontos de vistas diferentes: o do linguista e o do falante/locutor. Ao dar uma nova interpretação à questão da arbitrariedade e daquilo que há de contingente no signo linguístico, Benveniste defende que do ponto de vista do locutor, não há como se falar de arbitrariedade, pois o locutor/sujeito só tem acesso ao signo positivado e já constituído nas condições de uso e no ato mesmo da enunciação, da fala, uma vez que o signo não existe a priori, ou seja, antes de seu emprego efetivo na língua enquanto ato de fala.

Ainda devemos ressaltar que a ação da consciência do sujeito falante é atribuir valores aos signos colocando o "balão no ar" e atribuindo a eles sentido, já que o signo só é signo por essa consciência, que tem o papel fundamental de interpretar a língua e por ela ser interpretada. E aí que o locutor se enuncia, pois como afirmam Saussure (2002) "só existe linguisticamente aquilo que é percebido pela consciência, isto é, aquilo que é ou se torna signo" (p. 45) [...] "pois uma palavra só existe verdadeiramente, e a partir de qualquer ponto de vista em que nos coloquemos, pela confirmação que ela recebe a todos os momentos daqueles que a empregam." (p. 83).

Da reflexão de Cunha (2008) podemos elencar alguns pontos importantes em relação ao signo saussuriano que nos levam a conclusão adiante. Esses pontos são: a noção de signo conduz às noções de valor e do sujeito falante ainda em Saussure; Saussure não teorizava exatamente sobre signos, mas sobre valores; fora do uso, o signo não existe, mas apenas no momento de seu emprego, no corte, no discurso; o falante não percebe nem a forma nem a ideia, mas a relação, por isso para o falante a relação entre o signo não é arbitrária, mas necessária, para que haja compreensão intersubjetiva, como bem destacou Benveniste; a língua é um sistema de valores, por isso as unidades empíricas da língua são os valores que são lidos como signos; os valores só existem baseados na consciência do sujeito falante, é esse sujeito que coloca o balão no ar.

Trouxemos nesta última seção as referências aos manuscritos por concordar com Depecker (2012) sobre o fato de que esses têm uma valiosa contribuição para o tema da discussão sobre a relação arbitrária e necessária do signo linguístico e a posição do sujeito falante na teorização saussuriana. O autor defende, e seguindo os passos dele, afirmamos que aquele não ultrapassa este, uma vez que para Saussure, o fato de haver uma necessidade de o sujeito passar pela relação interna entre a imagem auditiva e o conceito indicaria um vínculo, ou uma aproximação entre os dois. Depecker (2012) nos traz a citação dos Escritos que, segundo ele, ilustra essa afirmação, a saber, "a relação pela qual em

\footnotetext{
${ }^{12}$ Durante todo o texto citamos a tradução que foi utilizada por nós como referência. No entanto, faz-se mister lembrar que o texto original de Benveniste é datado de 1939.
} 
linguística o som desperta a ideia, ou reciprocamente, é uma relação arbitrária em sua primeira origem." (DEPECKER, 2012, p. 105).

Para Saussure, argumenta o autor, "sua primeira origem" destaca exatamente aquilo que é indissociável, não pode, por assim dizer, ser totalmente arbitrário. Mesmo que o significado e o significante sejam, em sua origem, radicalmente arbitrários, apresentam-se na consciência do sujeito falante como indissoluvelmente unidos. De onde concluímos: assim como em Benveniste, o sujeito e o discurso já estavam em Saussure mesmo no CLG, quando o autor afirma que é o sujeito falante o nicho da linguagem e da língua.

\section{Referências}

AGUSTINI, C.; LEITE, J. Benveniste e a teoria saussuriana do signo linguístico: o binômio contigência-necessidade. Língua e Instrumentos Linguísticos, v. 30, p. 113-129, 2012.

BENVENISTE, É. Problemas de Linguística Geral I. São Paulo: Editora Nacional, Ed. da Universidade de São Paulo, 1976.

BENVENISTE, É. Problemas de Linguística Geral II. São Paulo: Pontes, 1989.

BOUQUET, S. Introdução à leitura de Saussure. Trad. Carlos Augusto Leuba Salum e Ana Lúcia Franco. São Paulo: Cultrix, 2000.

CUNHA, R. B. A relação Significado e Significante em Saussure. ReVEL. Edição especial, n. 2, p. 1-12, 2008.

DEPECKER, L. Compreender Saussure a partir dos manuscritos. Trad. Maria Ferreira. Petrópolis: Vozes, 2012.

FARIA, N. R. B. Entre a leitura da fala e a escrita da língua: o fonema em Saussure. DELTA, v. 34, n. 3, p. 861-890, 2018. https://doi.org/10.1590/0102-445056793643281893

FIORIN, J. L. O projeto semiológico. In: FIORIN, J. L.; FLORES, V. do N.; BARBISAN, L. B. Saussure: a invenção da linguística (orgs.). São Paulo: Contexto, 2013. p. 99-112.

FLORES, V. do N.; BARBISAN, L. B. (orgs.). Sobre Saussure, Benveniste e outras histórias da linguística. In: NORMAND, C.; FLORES, V. do N.; BARBISAN, L. B. Convite à linguística (orgs.). São Paulo: Contexto, 2012. p. 7-22.

FLORES, V. do N.; ENDRUWEIT, M. A noção de discurso na teoria enunciativa de Émile Benveniste. Revista Moara, n. 38, p. 196-208, 2012.

https://doi.org/10.18542/moara.v1i38.1280

KOYRÉ, A. Do mundo fechado ao universo infinito. Tradução de Donaldson M. Graschagem. 2a edição - Rio de Janeiro: Forense-Universitária: São Paulo: Ed. Da Universidade de São Paulo, 1986.

LIMA, H. O Curso de Linguística Geral e os Manuscritos saussurianos: unde exoriar? - In.: Saussure: a invenção da linguística/ José Luiz Fiorin, Valdir Nascimento Flores e Leci Borges Barbisan (orgs). - São Paulo: Contexto, 2013. p. 59-70.

MILNER, J-C. Introduction à une Science du langage (version abrégée). Paris: Éditions du Seuil, 1995. 
MILNER, J. C. Le périple strutural: figures et paradigmes. Nouvele édition revue et augmentée. Paris: Editions Verdier, 2008

MILNER, J. C. O amor da língua. Campinas: Editora da Unicamp. 2012.

NEUMANN. D.; ANJOS. A. G. Dos limites da redução do pensamento saussuriano ao movimento estruturalista. Leitura, Maceió, v. 1, n. 62, p. 330-332, 2019. https://doi.org/10.28998/2317-9945.2019v1n62p315-332

NORMAND, C. Os termos da enunciação em Benveniste. In: OLIVEIRA, S. L.; PARLATO, E. M.; RABELLO, S. (orgs.) O Falar da Linguagem (Série linguagem). São Paulo: Lovise, 1996. p. 127152.

NORMAND, C. Allegro ma non troppo: invitation à la linguistique, Paris: Ophrys, 2006.

NORMAND, C. Saussure. Trad. Ana de Alencar e Marcelo Diniz. São Paulo: Estação Liberdade, 2009.

NORMAND, C. Saussure-Benveniste. Convite à linguística; Valdir do Nascimento Flores e Leci Borges Barbisan (orgs.); tradução de Cristina de Campos Velho Birck et al. São Paulo: Contexto, 2012. p. 197-204.

NUNES. P. A. Émile Benveniste, leitor de Saussure. Cadernos do IL. n. 42, p. 51-63, 2011. https://doi.org/10.22456/2236-6385.26004

ROSÁRIO. H. M. Émile Benveniste e a dupla significância da língua: a distinção semiótico/semântico. Desenredo. Revista do Programa de Pós-Graduação em Letras da Universidade de Passo Fundo, v. 14, n. 3, p. 444-456, 2018. https://doi.org/10.5335/rdes.v14i3.8586

SAUSSURE, F. de; BOUQUET, S.; ENGLER, R. (orgs. e eds.). Escritos de Linguística Geral. São Paulo: Cultrix, 2002.

SAUSSURE, F. de. Curso de Linguística Geral. Tradução Antônio Chelini et al. 25. ed. São Paulo: Cultrix, 2003[1916].

SILVA FILHO, J. T. da. Linearização e hierarquia: retomando o paradoxo posicional a partir do programa minimalista. 2018. 146 f. Tese (doutorado em Letras e Linguística: Linguística) Universidade Federal de Alagoas. Faculdade de Letras. Maceió, 2018.

STUMPF, E. M. Saussure e Benveniste: Ultrapassagem ou rompimento? ReVEL, v. 8, n. 14, p. 1-12, 2010.

TESTENOIRE, P. Y. A linearidade saussuriana em retrospecto. Cadernos de Historiographia Linguística do CEDOCH, v. 2, p. 89-109, 2017.

Recebido em: 19/11/2019.

Aceito em: 09/03/2020. 